\title{
An Investigation of the Coping Strategies Used to Mitigate Burnout among Primary School Teachers in Kenya
}

\author{
Kenneth Otieno* \\ Department of Educational Psychology, Masinde Muliro University of Science \& Technology, \\ Kakamega, Kenya \\ *Corresponding Author: Kenneth Otieno, Department of Educational Psychology, Masinde Muliro \\ University of Science \& Technology, Kakamega, Kenya
}

\begin{abstract}
There is growing concern with the growth and prevalence of stress and burnout among teachers. Recent estimates suggest that teachers in Kenya are so demoralized, despised, frustrated and ridiculed that 30 to 40 per cent of them do not enjoy optimum health while 45 per cent experience burnout. It is against this background that this study investigated the coping strategies used to mitigate burnout among primary school teachers in Nyanza region. Kenya. The Ex-post facto research design was used to establish the relationship between the independent and dependent variables in the study. Purposive and stratified random sampling techniques were used to select the study sample. The population of the study was 399 primary school teachers drawn from 32 primary schools and 8 Sub County Quality Assurance and Standards Officers (SQASOs) in Nyanza region. Data was collected by means of both structured and unstructured questionnaires and in-depth interviews. Data analysis was performed using the Statistical Package for the Social Sciences (SPSS) Version 16.0. The two tailed t-test and product-moment coefficient of correlation were run to establish the differences and relationships between the independent and dependent variables. The level of significance was set at 0.05. Content analysis of the written free responses was also carried out. First, it was established that primary school teachers in Nyanza region experience high levels of burnout. The burnout syndrome among Nyanza teachers appear to be most prevalent in the form of emotional exhaustion and reduced personal accomplishment. Second,teachers in Nyanza region lack adequate self-efficacy and organizational techniques that can be used as intervention strategies to mitigate experienced burnout. It is recommended that individual teachers, educational management personnel, planners and policy makers should have an informed understanding of burnout and its early warning signs hence equip themselves with skills, abilities, behaviours, conflict management and resolution policies and strategies needed to minimize incidences of burnout.
\end{abstract}

Key words: Burnout, Depersonalization, Diminished Personal Accomplishment: Emotional Exhaustion, Self efficacy

\section{INTRODUCTION}

In the teaching profession today, there is a global concern with the growth and prevalence of stress and burnout among teachers. The teaching profession has become increasingly challenging and complex. Enough evidence exist to show that teaching is one of the most complicated and stressful occupations (Gillian, 2007; Ingersoll, 2012; Mooney, 2018). Researchers indicate that teachers continually face increasing workloads, larger class sizes, unmotivated and undisciplined pupils, minimal parental or administrative support, and decreasing resources to highlight a few ( Espin \& Weissenburger, 2001; Hastings \& Bham, 2003). This inevitably leads to the development of burnout which is a phenomenon that is suffered by teachers (Cherniss, 1980a; Hughes, 2001).

According to Jackson and Rothmann (2005a), educators experience a great deal of stress and burnout practically on a daily basis. The impact of this on teachers' mental and physical health is decidedly negative (Tang, Schwarzer \& Schmitz, 2001; Pomaki \& Anagnostopoulou, 2003; Antoniou, Polychroni \& Vlachakis, 2006) and may lead to psychological dysfunction (Griva \& Joekes, 2003). Consequently, stress and burnout among teachers have received considerable research attention across the globe (Antoniou et al., 2006; Stevenson \& Harper, 2006; Ingersoll, 2012; Mooney, 2018).

The teaching environment deals with close human interactions inter alia teacher-pupil, teacher-parent and teacher-teacher relations. These close contacts inevitability render teachers more susceptible to 
high emotional exhaustion, depersonalization and low personal accomplishment. According to Wangai (2012), teachers in Kenya are so demoralized, despised, frustrated and ridiculed that 30 to 40 per cent of them do not enjoy optimum health while 45 per cent experience burnout.

For the purpose of this study, burnout is used to refer to a situation in which what was formerly a 'calling' becomes merely a 'job'. One no longer lives to work but works only to live. In other words, the term refers to loss of enthusiasm, excitement and a sense of mission in one's work. Given this situation, the teacher experiences physical, mental and emotional exhaustion characterized by the negation of oneself, one's environment, one's work and one's life. It results from prolonged experience of stress.

The focus of this study is to investigate the coping strategies used to mitigate burnout among primary school teachers in Nyanza Region, Kenya. The region has continued to post poor results since the inception of Kenya Certificate of Primary Examination. In fact in the early 1980s, the province used to lead in the primary school examinations nationally hence, the need to establish the possible reasons for the decline in academic standards at this level.

It has been argued that workplace-based interventions aimed at reducing stress and modifying some of the maladaptive responses to stress often has little or no effect (Briner \& Reynolds, 1999). The question one needs to ask is whether this conclusion is relevant to interventions designed to ameliorate experienced burnout. Most of the burnout interventions reported in the literature are individual-oriented and provide treatment, not prevention, much like other stress interventions (Nelson, Quick \& Simmons, 2001). There are hardly any reports on interventions that were based on a systematic audit of the structural sources of burnout with the objectives of alleviating or eliminating the stresses leading to this experience.

Albee (2000), one of the pioneers of prevention research points out that, 'it is acceptable public health doctrine that no disease or disorder has ever been treated out of existence' (p. 874). To this end therefore it is imperative that the roots of burnout are identified and where possible be eliminated before the syndrome develops than to treat it after it has already occurred.

Many researchers (Grosch \& Olsen, 1994; Wanjiru, 2006) have compared people who cope with stress mechanisms by minimizing or avoiding it to those who use more confrontational or vigilant strategies, such as gathering information and taking action. Individuals who directly deal with a problem may not only solve the problem but are also better prepared to handle stress in future. (Felton, Revenson \& Hinrichsen, 1984; Quinn, Fontana \& Reznikoff, 1987).

The seriousness of burnout is seen in terms of maiming the individual and making them acquire intrapersonal conflicts, inadequacies and internal disabilities in terms of effective coping. It is clear that burnout threatens the ethical principles of respect for the dignity of persons, responsible caring, concern for other's welfare, and responsibility to society. Burnout affects all aspects of a teacher's functioning. Its effects are pervasive and ethically dangerous. Its symptoms can lead to incompetent care, boundary violations, disrupted relationships, increased conflict and various health problems for teachers. It is against this background that a systematic study was needed to address this gap and shed light on the coping strategies employed by primary school teachers in Nyanza region, Kenya to mitigate experienced burnout.

\section{RESEARCH METHODOLOGY}

The current study combined both quantitative and qualitative designs which is described as methodological pluralism. Basically, primary school teachers were selected for the study because they are charged with the responsibility of handling children during the formative stages of their development which is very important in shaping their future lives.

The research design adopted was Ex-post facto. This study design was selected mainly because besides collecting and describing the relevant data for the study, it explored the existence of certain relationships among the independent variable (burnout) and dependent variables (coping strategies).

The study was carried out in Nyanza region, Kenya. Nyanza region was selected because of the poor results pupils in public primary schools have been posting since the inception of KCPE. In fact in the 
early 1980s, the province used to lead in the primary school examinations nationally hence, the need to establish the possible reasons for the decline in academic standards at this level.

The population of the study was 3132 practicing primary school teachers drawn from 518 schools and 32 Sub County Quality Assurance and Standards Officers (SQASO's) spread across 32 Sub counties in Nyanza region. The study sample comprised 400 teachers, who were not head teachers, drawn from 32 public primary schools spread across 16 Sub counties in Nyanza region and 8 SQASOs. Public primary school teachers were selected because they are all hired by the same employer, the Teachers Service Commission and so they work under the same terms and conditions of service.

Purposive sampling technique was used to identify common characteristics of the schools in the study. Thereafter, the stratified random sampling technique was used to select the study sample. The sampling unit was the school. The schools were classified into rural and urban categories. From each stratum, one school was chosen at random using the random number table. This technique of sampling ensured that each of the given type of school was represented in the study.

In this study the proportion of the target population with a certain characteristic is .50 , the z-statistic is 1.87 , and the desired accuracy is at the 0.5 level, therefore, the sample size is calculated as follows.

$$
\begin{aligned}
n & =\frac{2.0)^{2}(.50)}{(.5)^{2}} \\
& =400
\end{aligned}
$$

From the sampled thirty two primary schools, all the 400 teachers employed by the Teachers Service Commission (TSC) completed the questionnaires. However, one teacher did not return the questionnaire hence final study sample comprised 399 teachers and 8 SQASO's who accepted to complete the questionnaires.

To collect data in this research, self-report questionnaires were used. Three questionnaires were used to collect data in this research. These were the Teacher Background Questionnaire (TBQ)) and the Maslach Burnout Inventory Form ED (MBI)which also provided an opportunity for the respondents to give free responses. This helped in validating responses from the respondents.

The teachers had an opportunity to write anonymously. The tools were self-administered, that is, the respondents were allowed to complete the instruments themselves, but within a designated time. Finally, an interview schedule for the SQASOs was used to collect data. All the research tools were piloted to ascertain their validity and reliability in the Kenyan situation. After collecting the questionnaire sheets, the following were done: editing, coding (every respondent was given an identifier number), categorization of variables (grouping together items measuring the same concept), keying data, interpretation and analysis. Informed consent and maintaining confidentiality were the ethical issues considered in this study. The researcher accurately represented what the respondents reported without biases.

Data analysis was mainly quantitative and less qualitative. The analysis of qualitative data involved immersion, categorization, phenomenological reduction and interpretation. To analyze quantitative data, different methods were used. First and foremost, frequency distribution tables were generated from data collected. Histograms were generated from the frequency distribution tables. These two methods of data presentation assisted in data interpretation and analysis.

After scoring the three questionnaires, the data was coded and data files prepared for computer analysis. The analysis was performed using the Statistical Package for the Social Sciences (SPSS) Version 16.0. The level of significance was set at 0.05 . Content analysis of the written free responses of the respondents was also carried out. The two tailed t-test was used to determine the difference between the independent and dependent variables. On the other hand, the product-moment coefficient of correlation was used to establish the relationships between the independent and dependent variables.

\section{RESULTS AND DISCUSSION}


An Investigation of the Coping Strategies Used to Mitigate Burnout among Primary School Teachers in Kenya

\subsection{Distribution of Male and Female Teachers}

Analysis was carried to show the distribution of male and female teachers. Table 1 shows the distribution of male and female teachers in the sample population.

Table1. Gender of the Respondents

\begin{tabular}{|l|l|l|}
\hline Gender & Frequency & \% \\
\hline Female & 230 & 58 \\
\hline Male & 169 & 42 \\
\hline Total & $\mathbf{3 9 9}$ & $\mathbf{1 0 0}$ \\
\hline
\end{tabular}

Overall, most $(58 \%)$ of the respondents in the sample were females teachers. Male teachers only accounted for $42 \%$ of the whole sample. This is a good example of the actual distribution of female and male teachers in Kenya. It appears that females have a more positive disposition towards the teaching profession than their male counterparts who seem reluctant to join the profession. Wanjiru (2007) believes women are more sociable, empathic and nurturing than men. Besides, they have better communication skills which are essential for the teaching profession.

\subsection{Distribution of Teachers by Age}

Analysis was also carried to show the distribution of teachers by age. Table 2 provides the age ranges of the sample population.

Table2. Age of the Respondents

\begin{tabular}{|l|l|l|}
\hline Age Group & Frequency & \% \\
\hline Below 21 Years & 0 & 0 \\
\hline $21-30$ Years & 149 & 37 \\
\hline $31-40$ Years & 128 & 32 \\
\hline Over 40 Years & 122 & 31 \\
\hline Total & $\mathbf{3 9 9}$ & $\mathbf{1 0 0}$ \\
\hline
\end{tabular}

The data in Table 2 shows that 37 percent of the teachers belonged to the 21 - 30 years age group. Those within the $31-40$ years age group accounted for 32 percent of the total sample. Teachers with forty years accounted for 31 percent of the total study sample. Teachers with over 30 years accounted for 63 percent of the total sample. This implies that most of the schools had older and perhaps mature teachers.

\subsection{Distribution of Teachers by Experience}

Information on the distribution of teachers in terms of years of teaching experience is shown in Table 3.

Table3. Years of Teaching Experience

\begin{tabular}{|c|c|c|}
\hline Years of Teaching Experience & Frequency & \% \\
\hline Less than 1 Year & 21 & 5 \\
\hline $1-5$ Years & 112 & 28 \\
\hline $6-10$ Years & 67 & 29 \\
\hline $11-15$ Years & 114 & $\mathbf{1 0 0}$ \\
\hline Total & $\mathbf{3 9 9}$ & \\
\hline
\end{tabular}

The results show that 28 percent of the teachers had between $1-5$ years of teaching experience. Those with fifteen or less years of teaching experience accounted for 71 percent of the total sample. On the other hand, those with over fifteen years of teaching experience accounted for 29 percent of the total sample. This shows that most of the teachers in the total sample had relatively fewer years of teaching experience.

\subsection{Distribution of Teachers by Locale}

Further analysis was carried out to establish the distribution of teachers by locale (rural or urban). Table 4 shows the distribution of teachers by locale.

Table4. Distribution of Teachers by Locale

\begin{tabular}{|c|c|c|}
\hline Location & Frequency & \% \\
\hline Urban & 290 & 73 \\
\hline
\end{tabular}


An Investigation of the Coping Strategies Used to Mitigate Burnout among Primary School Teachers in Kenya

\begin{tabular}{|l|c|c|}
\hline Rural & 109 & 27 \\
\hline Total & $\mathbf{3 9 9}$ & $\mathbf{1 0 0}$ \\
\hline
\end{tabular}

Data presented in Table 4 shows that 73 percent of the respondents were drawn from the urban centres. Only 27 percent of the total teachers sampled were from rural areas. From this distribution we can conclude that most teachers prefer working in urban areas. This is probably due to the fact that the urban areas have better amenities when compared with the rural areas. These may include better equipped hospitals, libraries, recreation and internet facilities which may not be easily available in rural areas.

\subsection{Distribution of Teachers by Marital Status}

Analysis was done to establish the marital status of the teachers. Table 5 shows the distribution of teachers by their marital status.

Table5. Distribution of Teachers by Marital Status

\begin{tabular}{|c|c|c|}
\hline Marital Status & Frequency & \% \\
\hline Married & 327 & 82 \\
\hline Single & 61 & 15 \\
\hline Separated /Divorced & 6 & 2 \\
\hline Widowed & 5 & 1 \\
\hline Total & $\mathbf{3 9 9}$ & $\mathbf{1 0 0}$ \\
\hline
\end{tabular}

From Table 5, it is evident that most $(82 \%)$ of the teachers were married while 15 percent of the respondents were single. Also, 2 percent of the respondents were either separated or divorced and a paltry 1 percent was widowed. From the results, it is clear that most teachers preferred marital and family lifestyles. It is basically important for teachers to maintain a balance between their personal and professional lifestyles (Skovholt, 2001). Having a supportive spouse and family provides the teacher with basic social support system. The situation may be grim for those who have either lost their spouses or are separated or divorced given the stresses that accompany such situations. Since teachers experience a lot of stress while on duty, a safe haven and secure base outside school is helpful. This can be in relationships with co-workers, supervisors, and supportive marital partners.

\subsection{Distribution of Teachers by Qualification}

The distribution of teachers in terms of their level of qualification is given in Table 6 .

Table6. Qualification of the Teachers

\begin{tabular}{|c|c|c|}
\hline Qualification & Frequency & \% \\
\hline P1 & 288 & 72 \\
\hline Diploma & 36 & 11 \\
\hline B.Ed & 42 & 1 \\
\hline Masters & 4 & 7 \\
\hline Others (ATS 1,2,3,4) & 29 & $\mathbf{1 0 0}$ \\
\hline Total & $\mathbf{3 9 9}$ & $\mathbf{1}$ \\
\hline
\end{tabular}

The data shows that most $(72 \%)$ of the teachers are P1certificate holders. Those with Bachelors in Education degree accounted for 11 percent while those with a Diploma accounted for 9 percent. The teachers with other qualifications accounted for 7 percent whereas a paltry 1 percent of the respondents had Masters Degree. This shows that majority of the teachers have the required qualifications to teach in primary schools. The fact that some of the teachers even had Bachelors and Masters degrees is a clear indication of the desire to attain competence through further training. Corey et al. (2003) suggest that training is a basic component of a professional's competence.

\subsection{Distribution of Teachers by Number of Lessons Taught Per Week}

The number of lessons taught by the teachers per week is shown in Table 7.

Table7. Number of Lessons Taught per Week

\begin{tabular}{|c|c|c|}
\hline Number of Lessons & Frequency & \% \\
\hline Below 20 & 28 & 7 \\
\hline $21-30$ & 117 & 29 \\
\hline
\end{tabular}


An Investigation of the Coping Strategies Used to Mitigate Burnout among Primary School Teachers in Kenya

\begin{tabular}{|c|c|c|}
\hline Over 30 & 254 & 64 \\
\hline Total & $\mathbf{3 9 9}$ & $\mathbf{1 0 0}$ \\
\hline
\end{tabular}

From the data, it is clear that 64 percent of the teachers from the total sample taught over 30 lessons per week. Only 29 percent of the teachers taught between 21 and 30 lessons. A paltry 7 percent of the teachers taught below 20 lessons. From the above findings we can conclude that the majority of teachers have a relatively heavy teaching load. Increasingly, teachers have also been expected to take on additional responsibilities besides that of teaching. Teachers are engaged in sports coaching and other co-curricular activities, which often result in work overload. An accumulation of such duties add more stress to the job, contributing to subsequent burnout.

\subsection{Distribution of Teachers by Distance Travelled to and from School}

The distance covered by teachers to and from school during a typical working day is shown in Table 8 .

Table8. Distance Covered by Teachers

\begin{tabular}{|c|c|c|}
\hline Distance $(\mathbf{K m})$ & Frequency & \% \\
\hline Less than $1 \mathrm{~km}$ & 100 & 25 \\
\hline $2-3 \mathrm{Km}$ & 116 & 29 \\
\hline $4 \mathrm{Km}$ and above & 123 & 46 \\
\hline Total & $\mathbf{3 9 9}$ & $\mathbf{1 0 0}$ \\
\hline
\end{tabular}

Table 8 shows that 46 per cent of the teachers travel over 3 kilometres to and from school. Those who travel between 2 and 3 kilometres accounted for accounted for 29 percent while those who travelled below 1 kilometre accounted for 25 percent. This implies that majority of the teachers do not work very far from their residences.

Analysis was carried out to establish the methods used by teachers in Nyanza region to mitigate experienced burnout. The hypothesis was stated as follows:

$\mathrm{H}_{\mathrm{A} 4}$ : Teachers in Nyanza region do not have adequate self-efficacy and organizational techniques to mitigate experienced burnout.

When the respondents were asked to indicate the strategies they used to cope with stressful situations, it emerged that most (92\%) of the teachers do not employ self-care methods such as having regular exercises, rest, meditation and medical check-ups to overcome stressful situations. A paltry (8\%) of the respondents indicated that they had taken study leave, were able to take a holiday with their families, eat a balanced diet and create time for entertainment. From follow up interviews, teachers said that they had no time for regular exercises, meditation and entertainment. Since the teachers are not adequately remunerated, they are not able to take a holiday with their families. Besides, during the first and second term school holidays the teachers have to organize for holiday coaching (tuition) for their learners. This extra work adds strain and stress on the teachers.

Table 9 gives methods of resolving burnout as suggested by the SQASO's.

Table9. Intervention Strategies for Burnout

\begin{tabular}{|l|l|l|}
\hline Method of resolving OT & Frequency & $\mathbf{\%}$ \\
\hline Self Care & 8 & 100 \\
\hline Social Support & 7 & 87.5 \\
\hline
\end{tabular}

Data in Table 9 shows that all (100\%) the respondents reported that self-care is vital in the management of occupational tedium. Seven $(87.5 \%)$ suggested social support systems. This indicates that there is a general need for self-care and social support as intervention strategies for burnout.

Self-care is one of the primary methods of preventing and treating teacher burnout. Self-care consists of integrating one's mental, emotional, physical, and spiritual well-being (Faunce, 1990, cited in Porter, 1995). Self-care of the teacher is mostly an issue of responsible caring. Self-awareness of how a teacher's own pressures, issues, and stress influence clients helps to improve the care of those clients. Teachers must also "Seek appropriate help and/or discontinue scientific or professional activity for an appropriate period of time, if a physical or psychological condition reduces their ability to benefit and not harm others" (CPA, 2000, II.11). One takes time for oneself only if conditions are negatively influencing one's professional performance. 
Teachers continue to perform their duties with pupils yet their judgment is likely to be impaired due to mental, emotional, or physiological conditions or as a result of experiencing tedium. It is unethical to practice while experiencing conditions that impair therapeutic performance. Teachers do engage in self-care activities that help to avoid conditions such as burnout that could result in impaired judgment and interfere with their ability to benefit and not harm others. Lack of self-care is unethical since it can lead to impaired judgment and performance. Such impairment is unethical as it can lead to harming clients. This impairment leads to questioning the competency of a teacher. Incompetent action is unethical as it is unlikely to be of benefit and likely to be harmful to clients.

The few teachers who practice self-care perhaps do not do it under the principle of respect for the dignity of persons. Certainly, this includes self-respect of the teacher as well as respect for clients. They do not carry out this responsibility in a manner that includes an awareness of and respect for their own needs.

There are many methods, strategies, and techniques available to teachers to help them achieve their self-care goals yet they do not use them. Guy (1987) suggests that reducing stress and dissatisfaction while taking proactive steps to rejuvenating teachers on an on-going basis is the most useful approach to preventing and treating tedium. Self-care is one method of achieving these goals. Teachers do not take steps before problems occur to increase available coping resources in preparation for the causes and symptoms of burnout. Teachers are not motivated to ensure a balanced and healthy lifestyle. They fail to take aggressive measures to reduce or eliminate those personal and environmental stresses which have the potential to negatively influence their personal and professional lives.

The few strategies teachers use to manage burnout include: self-monitoring and awareness of a problem, identification of stressors, accurate appraisals of transactions with the work environment, commitment to action, and acquiring or enhancing personal coping resources. According to Norcross (2000) it is important to have a variety of self-change skills and one should embrace multiple strategies, even if they are from diverse theoretical orientations.

Self-Awareness is central to preventing burnout (Patrick, 1981). One of the most important steps in managing burnout is recognizing the signs and symptoms of burnout(Muldary, 1983). Self-care requires self-awareness: one needs to know when one feels stressed and when it is time to seek help (Maslach, 1986). Awareness of how one tends to respond to stress also provides a database against which to measure change and growth. Self-awareness is the first step in self-care that combats burnout(Norcross, 2000). Without self-awareness, teachers may never be motivated to engage in selfcare to help prevent and treat burnout.

Whereas relaxation, exercise, and diet are frequently mentioned methods of self-care that help prevent and treat burnout the teachers do not take these into account. When one is operating under optimal physical and psychological health, one is better able to handle stress (Maslach, 1986). Physical health and exercise, as well as adequate opportunities for rest and relaxation are essential for maintaining a sense of stability and well-being (Guy, 1987). Teachers have demanding jobs and it is important for them to have time for recharging, rest, and relaxation (Maslach, 1986). Relaxation reduces fatigue and aches, decreases stress responses, replenishes energy, enhances the ability to fall asleep and sleep soundly, and facilitates an overall sense of calmness and well-being (Patrick, 1981).

Teachers do not go for meditation as method of reducing stress. Basically, meditation is an excellent form of self-care as it helps people relax by slowing the frantic pace of living (Patrick, 1981). Research has shown that adequate exercise and relaxation are effective in reducing burnout among teachers (Guy, 1987). A well-balanced program of entertainment and exercise has led to less tburnout among teachers (Guy, 1987). Diet is also important as it increases one's energy and makes it easier for one to relax (Muldary, 1983). One needs to pay attention to one's physical health through preventive care, such as going to a doctor and dentist regularly for check-ups (Patrick, 1981). Improving and maintaining one's physical health is an effective self-care method as it increases one's energy, sense of well-being, and ability to deal with stress effectively. Balancing professional activities with a life outside of work is an important form of self-care (Norcross, 2000).

Teachers often do not receive direct feedback and gratification from their work. Besides, they do not have sources of gratification other than work, such as reading, watching movies, and sports. Taking part in an enjoyable activity also replenishes one's energy resources, reduces tension, and makes 
relaxation easier (Whitfield, 1980; Patrick, 1981). A reduced sense of accomplishment resulting from experienced burnout may lead to even more extreme feelings of inadequacy, failure, depression, and low self-esteem (Maslach, 1986). Satisfaction gained through leisure activities may help alleviate many of the subjective symptoms of burnout, including emotional exhaustion, decreased self-esteem, feeling trapped, emotional withdrawal, depression, boredom, and increased isolation. Engaging in leisure activities is an important part of any self-care program and has many beneficial effects in preventing and treating burnout.

Individuals with adequate coping strategies are less likely to experience high levels of burnout (Patrick, 1981). Developing and using coping strategies is therefore an important method of self-care. Coping strategies are the "ability to draw on emotional, physical, and social resources that allow one to avoid the adverse impact of stress." (Patrick, 1981 p. 46). When dealing with burnout, one may need to engage in direct coping strategies, including confronting the source of stress, changing oneself, and changing the environment. Some concrete coping strategies include: reappraisal of goals, time management, acknowledging vulnerabilities, compartmentalizing life and work, selfreinforcement, and a change of attitude (Muldary, 1983).Training in assertion and conflict resolution may also help people cope with stress due to interpersonal relationships (Patrick, 1981). Developing and engaging in coping strategies is one self-care method that acts directly to prevent and treat burnout.

In dealing with burnout, one needs support from self, personal relationships, and work structure (Jaffe, 1986). One needs a support network where one can express one's emotions. Expression of emotions decreases the isolation and loneliness that often result from burnout(Patrick, 1981). Emphasizing the interpersonal element in one's self-care and utilizing various helping relationships seems to be beneficial (Norcross, 2000). Healthy friends and family are an extremely important support to have (Whitfield, 1980). Seeking personal therapy is a method of gaining support that a majority of teachers have engaged in (Norcross, 2000). There are also many support strategies that an organization may use to prevent and combat burnout in its employees (Patrick, 1981). These include having a clear and consistent communication style, planning self-care programs, assessing burnout, educational opportunities, methods of acknowledgement, psychological support options, mental health days, and fitness programs.

Many professional groups have developed programs for impaired professionals, but this is not yet the case in the field of psychology (Nathan, 1986). Developing and using a strong support network is one component of self-care that is likely to help prevent and treat tedium. One's work environment can contribute to tedium. Modifying the work environment is another useful way of combating tedium through self-care. When possible, teachers should engage in stimulus control (Norcross, 2000). Stimulus control consists of manipulating antecedents and consequents to increase the probability of desired behaviours occurring (Walker, Greenwood, \& Terry, 1994). The frequency with which teachers modify their environments to work for and not against them using stimulus control consistently correlates with teacher effectiveness (Norcross, 2000). One may not need to work harder, but smarter to deal with tedium. One can achieve this through changing work patterns, styles, and/or routines (Maslach, 1986).

The teachers do not diversify professional activities as method of self care, as job monotony can contribute to burnout. Poor work relations, little or no work sharing, a lack of social feedback, no legitimized time out from client contact, and little or no peer support correlated highly with social service worker burnout (Pines \& Kafry, 1978, cited in Leon, Altholz, \& Dziegielewski, 1999). Therefore, good work relations, work sharing, feedback, time away from clients, and peer support should be in place to counteract. Patrick (1981) outlined several personal strategies to use to prevent and combat burnout. These include peer support groups, peer contracting, mini-vacations, setting limits, acknowledgement, personalizing one's workspace, and decompression periods.

The teachers do not appreciate the rewards of being a teacher. The teaching profession brings joy, meaning, growth, excitement, and vitality to both the teacher and the client. Modifying how one interacts with one's work environment and focusing on the positive aspects of one's work are beneficial components of teacher self-care. 
Many cognitive factors influence one's experience of burnout. Individuals with an external locus of control may feel helpless and powerless, and may thus be more susceptible to burnout than those with an individual locus of control that may take a more active stance in dealing with stress (Patrick, 1981). Changing one's attitudes towards responsibility and control for one's experiences may be one method of self-care to prevent and treat burnout. Unrealistic expectations may also increase one's risk for burnout. Effective self-care may include setting more realistic expectations and goals for oneself (Maslach, 1986).

The teachers apparently do not appreciate goal setting which can help reduce tedium because it acknowledges personal accomplishments. Wishful thinking reduces problem solving and accentuates distress; self-blame causes more distress and may paralyze the teacher's adaptive resources (Norcross, 2000). Teachers do not examine and modify their cognitions that relate to burnout as part of their selfcare efforts.

Most (84\%) of the respondents reported that there were peer support groups in their schools. The teachers indicated that the school administration encouraged them to establish staff welfare groups. The percentage of teachers who had attended workshops and conferences was only ten. This implies that most of the teachers do not receive training on key aspects such as assertion and conflict resolution which are important in managing experienced burnout The respondents who reported that they have opportunities to receive biofeedback accounted for only four per cent. A paltry (2\%) of the respondents indicated that their schools provided recreational facilities for teachers.

Basically, teachers have managed to ameliorate experienced burnout by establishing strong peer support groups. In a longitudinal research of burnout among teachers, Brouwers and Tomic (2000) found that emotional exhaustion had a negative effect on self-efficacy beliefs and that this effect occurred simultaneously rather than over time. They (Brouwers \& Tomic, 2000) reasoned that interventions that incorporate enactive mastery experiences, the most important source of self-efficacy beliefs, were likely to have an ameliorative effect on teachers' emotional exhaustion. An example would be having teachers learn and experiment with skills to cope with disruptive students behaviours. In the same vein, the environmental sense of control is an important stress management resource Fisher, 1984).

Those with a high sense of control tend to use their resources judiciously, relying on themselves when this is deemed most appropriate and using available social support when this is the more effective coping route. According to Hobfoll \& Shirom (2000), interventions that combine both social support and bolstering of control may be more efficacious in reducing occupational in organizations. For example, a multifaceted intervention that combined peer social support and bolstering of professional self-efficacy was found to reduce burnout relative to a control group of non-participants (Rabin et al., 2000). Yet another example is the study of Freedy and Hobfoll (1994), which enhanced nurses' coping skills by teaching them how to use their social support and individual mastery resources and found a significant reduction in emotional exhaustion in the experimental group relative to the nontreated control group.

Furthermore social support has been seen as useful resources to let individuals cope with stress efficiency. Individual who have supportive social relationship are able to rely on others to help them to deal with some problems in stressful situations, hence they perceive less stress and are least affected by it. In contrast, people who lack of supportive social relationships are vulnerable to the effects of stress (Russell, Altmaier \& Velzen, 1987).

As has been reported in the study, the quality of work relationship with is a major source of stress at work. The nature of the relationship with the head teacher, and colleagues can be a major source of stress at work. A trusting and caring environment in the schools is lacking. Naturally, burnout cannot be reduced if a does not have good work relationship with others and better support systems at work. When an individual has good work relation and support from others, their advice and support may reduce tension. It helps an individual to achieve distance from the stressful situation and perceive a sense of shared responsibility. Given this situation the individual will be less prone to burnout (Pines \& Aronson, 1988). 
Cordes and Dougherty (1993) indicated that the effect of social support on stress and burnout have received extensive attention in literature. Social support has been identified have a role to buffer jobrelated stress. Social support can make individuals have perception that they can cope with the situations by increasing their perception that others will provide the necessary resources. Greater perceived social support from co-workers or supervisor is associated with lower reported levels of burnout

Similar findings were reported by Baker and O'Brien (2007) who indicated that supervisor and coworker support are important sources of social support, relating to lower level of burnout in the workplace. Rebecca and Wendy (2007) also indicated that supervisors and work colleagues are able to provide support in the form of relevant information and feedback, practical assistance and emotional support relevant to the stressful work situation. This can help an individual have more confidence in solving burnout. Teachers with receive social support from supervisors reported less emotional exhaustion, more positive attitudes and greater personal accomplishment.

Cordes and Dougherty (1993) indicated that social support may cause the individual to redefine the bad situation at work and enhance the individual's perceived ability to cope with the demand induced by the stressful workplace.

Maslach, Schaufeli and Leiter (2001) indicated that social support is one source of job resources; they indicate that job resources can acts as buffer effect from the process of job demand and burnout. In this result, it indicated that lack of social support is linked to occupational tedium. Hasida and Keren (2007) mentioned that social support at work was negatively related to exhaustion, depersonalization and positively related to personal accomplishment.

When asked to identify which factors they found most frustrating about teaching in a primary school, they cited; poor remuneration (87\%), heavy workload (64\%) and lack of support and recognition from the head teachers $(42 \%)$. On the other hand when they were asked to identify three things that ought to be done to make teaching more attractive they cited the following: First, an improvement in remuneration, second giving the teaching profession recognition and finally the need to provide teachers with the relevant teaching and learning resources to enhance performance.

According to Greenberg (1999), are three levels of prevention interventions. The first level is primary intervention. Here, the goal is to reduce the incidence of new cases of the disorder. Basically, organizational practices that prevent occupational tedium among teachers are generally those that allow teachers some control over their daily challenges. At the individual level, self-efficacy and the ability to maintain perspective in regard to daily events have been described as anxiety buffers (Greenberg, 1999). The development of self-efficacy enhances one's resiliency in the face of life stressors. Howard \& Johnson, 1999 \& 2000a) investigated the strategies of resilient teachers in hard to staff schools. This qualitative study used structured interviews. Three target schools were approached and principals asked to identify teachers who were at risk of stress and burnout because of the nature of their work but were resilient. Results showed that there were many ways of coping with stress, which were located outside the individual. All the respondents had caring networks of family and friends outside school. They also had caring partners with whom they could discuss their work (Howard \& Johnson, 1999 \& 2000a). Besides, the teachers had strong support from colleagues and the school leadership.

An intervention frequently used by organizations attempting to ameliorate burnout amongst their employees is peer support groups. The theoretical perspective offered in this section may explain the focus of many interventions on enriching and strengthening the social support available to or utilized by employees experiencing occupational tedium. According to the predictions of Conservation of Resources (CoR) theory, the depletion of one's energetic resources and impoverished social support are closely related (Hobfoll, 1998).

Those lacking a strong resource pool, including those with impoverished social support, are more likely to experience burnout, or to go through cycles of resource loss when they cope with workrelated stress. Additionally, people with depleted energetic resources, who complain of physical fatigue, emotional exhaustion, and cognitive weariness, may appear to their significant others at work as less attractive and therefore less likely to have access to social support. There is considerable support for these arguments. In a review of the area of social support and stress, Curtona and Russell 
(1990) integrated four studies that had investigated the effects of social support on burnout among public school teachers, hospital nurses, therapists, and critical care nurses, respectively. In all four studies, negative associations between social support and burnout were found. For reasons explained above, these negative relationships may be reciprocal.

The peer social support intervention is particularly popular in educational institutions (e.g., Travers \& Cooper, 1996; Vandenberghe \& Huberman, 1999). Such peer-based support groups provide their members with informational and emotional support and in some cases instrumental support too (Burke \& Richardson, 2000). Since social support is a major potential route to resources that are beyond those that individuals possess directly, it is a critical resource in many employment-related stressful situations (Hobfoll \& Shirom, 2000) and may help them to replenish their depleted energetic resources. However, how social support is actually used is dependent on several factors, including one's sense of mastery and environmental control.

From studies in Australia on the incidence of teacher stress and burnout, the recommended primary palliative care to teachers includes consulting with teachers on matters related to their work, providing adequate resources and facilities in instructional practice, providing clear job descriptions and expectations in an effort to address role ambiguity and conflict and establishing and maintaining open lines of communication between teachers and administrators to provide administrative support and performance feedback that may act as a buffer against stress. It also involves allowing for and encourage professional development through mentoring and networking, engendering a sense of accomplishment and a fully developed professional identity, training teachers to de-personalize incidents and organizing strong and reliable behaviour management strategies. Finally, it involves providing support in both professional and personal issues, promoting strong peer group support, and celebrating staff achievement and giving promotions (Education Service Advisory Committee, 1998; Albee, 2000; Kyriacou, 2001).

Second, in secondary prevention, the goal is early identification and treatment of symptoms before they turn into full-blown disorder. On-going assessment helps in recognizing the early stages of occupational tedium and signs of susceptibility to it. An inventory to measure tedium can focus on personal variables in relationship to work.

Finally tertiary prevention is where persons who have recently suffered a disorder receive some type of intervention to present relapse (Cogne, 1991). Pines and Kafry (cited in Wanjiru, 2007) explored the relationship of burnout and coping among 231 physicians. The study found that active strategies were most effective in coping with burnout. The study recommends becoming aware of the problem, taking responsibility for doing something about the problem, achieving a degree of cognitive clarity about what can be changed and what cannot, and developing new tools for coping. Advanced experience of burnout may achieve the status of illness, like: clinical depression, heart attack, duodenal ulcer, ulcerative colitis or irritable bowel syndrome (William et al., 1992). In these cases medical treatment is crucial in dealing with the organic effects in the teacher.

\section{CONCLUSiON}

From the foregoing discussion, it is reasonable to conclude that there is a general need for teachers to adopt self care and social support as intervention strategies for burnout. Teachers must evaluate how their own experiences, attitudes, culture, beliefs, values, social context, individual differences, specific training, and stresses influence their interactions with others, and integrate this awareness into all efforts to benefit and not harm others.

Self-care effectively reduces these negative effects that are threats to ethical practice. Some methods of self-care are self-awareness, physical health, leisure activities, coping strategies, support networks, modifying one's work environment, and various other cognitive methods. Self-care protects clients from harm, promotes client self-care, and protects therapists from occupational hazards and stress (Porter, 1995). It improves the functioning and health of all individuals involved in all areas of their lives. Teacher self-care forms a foundation for health and ethical educational practice. If the work environment is enabling and rewarding and there is good support from significant others, resilience is developed. 
The head teacher and school management committees have a role to play in instituting preventive measures, including steps to ameliorate chronic work-related stress. Organizational interventions to reduce burnout have great potential, but are complex to implement and costly in terms of resources required. The changing nature of employment relationships, including the transient and dynamic nature of employee-employer psychological contract, entails putting more emphasis on individualoriented approaches to combat burnout. The role of individual coping resources, including selfefficacy, hardiness, and social support from friends and family, may become more important in future interventions. Therefore, the hypothesis that teachers in Nyanza region do not have adequate self efficacy and organizational techniques to mitigate experienced burnout is accepted.

\section{RECOMMENDATIONS}

Burnout undoubtedly has adverse personal and institutional consequences (Cordes \& Dougherty, 1993; Mirvis et al., 1999; Maslach et al., 2001). In view of the fact that burnout can be prevented and its undesirable effects reduced (Golembiewski et al., 1986), it follows that scholars will call for schools to assess the psychological status of their leaders and teachers.There is an equal, if not more pressing, need, however, to assess the prevalence and incidence of stress and burnout among the Kenyan teachers on a regular basis.

In the educational sector and, specifically, in primary education, the role of individual teachers is significant beyond description and the impact of educators on young learners, who probably spend more time during their childhood with their educators than with their parents, must be a critical consideration. Basically, the social, affective and cognitive development of learners in schools is impacted directly by teachers who are experiencing high levels of burnout. It is for these reasons that the phenomenon and consequences of burnout require further research. This phenomenon and its adverse effects should be debated among teachers and accorded an appropriately high priority on the national agenda for educational management. A thorough understanding of the causes of burnout is necessary if educational effectiveness and efficiency are to be secured, the loss of good teachers is to be curbed, conflict is to be reduced and the learning experience of learners is to be maximised.

It is important that individual teachers' asses each of the factors identified in this study which are important in producing burnout. This may help them to determine how to relate to these factors personally. For example, they would be able to identify early warning signs which are potential stressors for them. They would then take appropriate steps to reduce or avoid stressful situations.

Further, individual teachers need training in conflict resolution. They should be able to discern whether the conflict they are experiencing is intrapersonal or interpersonal or both. They require coping strategies, for example, using appropriate relaxation techniques. They can thus determine which techniques are effective for them individually or collegially.

Head teachers should develop strategies to prevent incidences of burnout through staff activities and the general organization and management of the school. They should make sure that the teachers have the necessary tools to implement new initiatives, consulting with staff and changes taking place in the school. When teachers experience an active, positive influence on policy decisions, burnout is reduced and job satisfaction is increased.

Kenya National Union of Teachers should not just be interested in the terms and conditions of service of teachers. It should be actively involved organizing informed forums to discuss challenges facing education and teachers welfare. This will help to exert professional influence on the thinking of the government and public on educational matters.

The government through the Ministry of Education has a vital role to play in reducing the incidence of burnout among teachers. They must acknowledge that such teachers are going through a negative experience, and are not very effective in their jobs. This is detrimental not only to the teachers themselves, but also to the children, school and staff. Such may even leave the profession all together.

Finally, as a suggestion for further research, this study may be replicated with different set of population such as private school.

\section{Acknowledgement}

Masinde Muliro University of Science and Technology 


\section{REFERENCES}

[1] Albee, G. W. (2000). "Commentary on prevention and counselling psychology." The Counselling Psychologist, 28, 845-853.

[2] Baker, L.M. \& O’Brien, K.M. (2007). “Are shelter workers burned out? An examination of stress, social support and coping.'” Journal of Family Violence, 22(6), 465-475.

[3] Briner, R. B., \& Reynolds, S. (1999). "The costs, benefits, and limitations of organizational level stress interventions." Journal of Organizational Behaviour, 20, 647-664.

[4] Brouwers, A. \& Tomic, W. (2000). “A longitudinal study of teacher burnout and perceived self-efficacy in classroom management.' Teaching and Teacher Education, 16, 239-253.

[5] Burke, R. J. \& Richardson, A.M. (2000). "Psychological burnout in organizations." In R. T. Golembiewski (Ed.). Handbook of organizational behaviour. (2 ${ }^{\text {nd }}$ Ed.; pp. 327-368). New York: Marcel Dekker.

[6] Cherniss, C. (1980a). Staff burnout: Job stress in the human services. Beverly Hills, CA: Sage.

[7] Cogne, R.K. (1991). "Gains in primary prevention: Implications for the counselling profession."' Journal of Counselling and Development, 69, 277-279.

[8] Cordes, C. L. and Dougherty, T.W. (1993). "A review and integration of research on job burnout." Academy of Management Review, 18, 621-656.

[9] Corey, G., Corey, M. \& Callanan, P. (2003). Issues and ethics in the helping professions. (6 $6^{\text {th }}$ edn.). New York: Brooks/ Cole.

[10] Curtona, C. E., and Russell, D. W. (1990). "Type of social support and specific stress: Toward a theory of optimal matching." In B. R. Sarason, I. G. Sarason, and G. R. Pierce (Eds.), Social Support: An Interactional View (pp. 319-361). New York: Wiley.

[11] Education Service Advisory Committee (1998). "Managing work-related stress: a guide for managers and teachers in the schools.' In Kyriacou, C. (2001). 'Teacher stress: Directions for future research.' Educational Review, 53(1), 27-35.

[12] Espin, C.A. \& Wissenburger, J.W. (2001). "Teaching students with learning disabilities: Perceptions of a first year teacher.' Journal of Special Education.35, 92- 99.

[13] Evans, M. (1996). “R.J. House’s `a path-goal theory of leader effectiveness.' Leadership Quarterly, 7(3), 305. Elsevier Science Publishing Company, Inc.

[14] Felton, B.J., Revenson, T.A. \& Hinrichson, G.A. (1984). "Stress and coping in the explanation of physical adjustment among chronically ill adults.' Social Science and Medicine, 18, 889-898.

[15] Fisher, S. (1984). Stress and the perception of control. London: Lawrence Erlbaum.

[16] Freedy, J. R., \& Hobfoll, S. E. (1994). "Stress inoculation for reduction of burnout: A conservation of resources approach.' Anxiety, Stress and Coping, 6, 311-325.

[17] Golembiewski, R. T., Munzenrider, R., and Stevenson, J. (1986). Stress in organizations. New York, New York; Praeger.

[18] Greenberg, J. S. (1999). Comprehensive stress management. (6th ed.). Boston: McGraw-Hill.

[19] Grosch, W.N. \& Olsen, D.C. (1994). When helping starts to hurt. London: W.W. Norton \& Company.

[20] Guy, J. (1987). The Personal life of the psychotherapist. New York: John Wiley and Sons.

[21] Hasida, B.Z. \& Keren, M. (2007). “Burnout, social support and coping at work among social workers, psychologist and nurses: The role of challenge/control appraisals." Social Work in Health Care, 45(4), 63-82.

[22] Hobfoll, S. E. (1998). The Psychology and Philosophy of Stress, Culture, and Community. New York: Plenum.

[23] Hobfoll, S. E., \& Shirom, A. (2000). "Conservation of resources theory: Applications to stress and management in the workplace', In R.T.

[24] Golembiewski (Ed.) Handbook of Organization Behaviour (2 ${ }^{\text {nd }}$ Revised Edition; pp. 57-81). New York: Dekker.

[25] Hastings, R. P. \& Bham, M. S. (2003). "The Relationship between Student Behaviour Patterns and Teacher Burnout.' School Psychology International [On-Line], 24, 115- 127, Retrieved July 18, 2007, from http://spi.sage.pub.com

[26] Hayes, D., Christie, P., Mills, M. and Lingard, R. (2004). "Productive leaders and productive leadership." Journal of Educational Administration, Vol. 42 No. 5, pp. 520-38.

[27] Howard, S. and Johnson, B. (1999). "Tracking student resilience.” Children Australia, Vol. 24 (3) pp. 14 - 23.

[28] Howard, S. and Johnson, B. (2000a). "What makes the difference? Children and teachers talk about resilient outcomes for students at risk.', Educational Studies, Vol 26 (3), pp 321- 327. 
An Investigation of the Coping Strategies Used to Mitigate Burnout among Primary School Teachers in Kenya

[29] Hughes, R.E. (2001). "Deciding to leave but staying: Teacher burnout, precursors and turnover.' [Electronic version] The International Journal of Human Resource Management, 12(2), 288-298.

[30] Ingorsoll, R. (2012). Beginning Teacher Induction: What Data Tells Us. Phi Delta Kappan, 93(8), 47-51 doi: 10, 1177/003172171209300811.

[31] Jackson, L.T.B., \& Rothmann, S. (2005a). "An adapted model of burnout for educators in South Africa." South African Journal of Education, 25, 100-108.

[32] Jaffe, D. T. (1986). The Inner Strains of healing work: Therapy and self-renewal for health care professionals, (pp. 194-208). New York: Brunner/Mazel Inc.

[33] Kyriacou, C. (2001). “Teacher stress: Directions for future research.”' Educational Review, 53 (1), $27-35$.

[34] Leon, A. M., Alholz, J. A. S., \& Dziegielewski, S. F. (1999). “'Compassion fatigue:

[35] Considerations for working with the elderly." Journal of Gerontological Social Work, 32, 44-62.

[36] Maslach, C. (1986). "Stress, burnout, and workaholism'. In R. R. Kilburg, P. E. Nathan, R. \& W. Thoreson (Eds.), Professionals in Distress: Issues, Syndromes, and Solutions in Psychology. Washington D.C.: American Psychological Association.

[37] Maslach, C., Jackson, S. E., \& Leiter, M. P. (1996). Maslach Burnout Inventory Manual (3rd Ed.). Palo Alto, CA: Consulting Psychologists Press.

[38] Maslach, C., Schaufeli, W. B. \& Leiter, M. P. (2001). “Job Burnout.' Annual Review Psychology, 52, 397- 422.

[39] Mirvis, D.M., Graney, M.J., \& Kilpatrick, D.P.A. (1999). “Trends in burnout and related measures of organizational stress among leaders of Department of Veterans Affairs medical centres." Journal of Healthcare Management, 44(5), 353-366.

[40] Mooney, J.M. (2018). The Relationship between Stress, Predictive Coping and Burnout among Elementary Teachers. Unpublished Masters Thesis. Eastern Illinois University.

[41] Muldary, T.W. (1983). Burnout and Health Professionals Manifestations and Management. Capistrano Press Norfolk, CT:

[42] Nathan, P. E. (1986). "Unanswered questions about distressed professionals." In R. Kilburg, P. E. Nathan, \& R. W. Thoreson (Eds.), Professionals in Distress: Issues, Syndromes, and Solutions in Psychology (pp. 27-36). Washington, DC: American Psychological Association, Inc.

[43] Nelson, D. L., Quick, J. C., \& Simmons, B. L. (2001). 'Preventive management of work stress: Current themes and future challenges.' 'In A. Baum, T. A. Revenson, \& J. E. Singer (Eds.), Handbook of Health Psychology (pp. 349-364). Mahawah, New Jersey: Erlbaum.

[44] Norcross, J. C. (2000). "Psychotherapist self-care: Practitioner-tested, research-informed strategies." Professional Psychology: Research and Practice, 31, 710-713.

[45] Patrick, R. K. S. (1981). Health care worker burnout: What it is, what to do about it? Chicago, IL: Blue Cross Association.

[46] Pines, A. \& Aronson, E. (1988). Career burnout: Causes and cures. New York: Free Press.

[47] Pomaki, G., \& Anagnostopoulou, T. (2003). "A test and extension of the demand/control/social support model: Prediction of wellness/health outcomes in Greek teachers.' Psychology and Health, 18(4), 537-550.

[48] Porter, N. (1995). "Therapist self-care: A proactive ethical approach'. In E. J. Rave \& C. C. Larsen (Eds.), Ethical decision making in therapy: Feminist perspectives (pp. 247-266). New York: The Guilford Press, Prentice Hall.

[49] Rabin, S., Saffer, M., Weisberg, E., Kornitzer-Enav, T., Peled, I., \& Ribak, J. (2000). “'A multifaceted mental health training program in reducing burnout among occupational social workers." Israel Journal of Psychiatry and Related Science, 37, 12-19.

[50] Raison, C.L. \& Miller, A.H. (2003). "When not enough is too much: The role of insufficient glucocorticoid signalling in the pathophysiology of stress-related disorders." The American Journal of Psychiatry, 160 (9), 1554-1565.

[51] Rebecca, S.L. \& Wendy, P. (2007). “Determinants of burnout among public hospital nurses.' Australian Journal of Advanced Nursing, 25(1), 8-16.

[52] Rebecca, S.L. \& Wendy, P. (2007). “Determinants of burnout among public hospital nurses.' Australian Journal of Advanced Nursing, 25(1), 8-16.

[53] Russell, D.W., Altmaier, E., \& Velzen, D.V. (1987). “Job-related stress, social support and burnout among classroom teachers." Journal of Applied Psychology, 72(2), 269-274.

[54] Stevenson, A., \& Harper, S. (2006). "Workplace stress and the student learning experience." Quality Assurance in Education, 14(2), 167-178.

[55] Travers, C.J., \& Cooper, C.L. (1996). Teachers under pressure: Stress in teaching. London: Routledge. 
An Investigation of the Coping Strategies Used to Mitigate Burnout among Primary School Teachers in Kenya

[56] Vandenberghe, R., \& Huberman, A. M. (1999). "Burnout and the teaching profession." In R. Vandenberghe \& A. M. Huberman (Eds.), Understanding and Preventing Teacher Burnout. A Sourcebook for International Research and Practice (pp. 111). Cambridge: Cambridge University Press.

[57] Walker, D., Greenwood, C. R., \& Terry, B. (1994). "Management of classroom disruptive behaviour and academic performance problems.” In L. W. Craighead, W. E. Craighead, A. E. Kazdin, \& Mahoney, M. J. (Eds.). Cognitive and Behavioural Interventions: An Empirical Approach to Mental Health Problems (pp. 215-234).

[58] William, R., Barefoo, J., Califf, R., Haney, J., Saunders, E., Pryor, D., Hratky, M., Siefler, I., \& Mark, D. (1992). "Prognostic importance of social and economic resources among patients with and documented coronary artery disease.' Journal of the American Medical Association 30, 267-520.

[59] Wangai, P. (2012), "Teaching on threshold of losing its glamour”. In K.Otieno, Leadersship Behaviour and Occupational Tedium among Primary School Teachers in Nyanza Region, Kenya. Unpublished Doctoral Thesis, Masinde Muliro Universityu of Science and Technology, Kakamega, Kenya.

[60] Wanjiru, G.C., (2006). 'Role of supervision in the management of counselor burnout.' Unpublished PhD thesis submitted to University of South Africa.

Citation: Kenneth Otieno. "An Investigation of the Coping Strategies Used to Mitigate Burnout among Primary School Teachers in Kenya" International Journal of Humanities Social Sciences and Education (IJHSSE), vol 7, no. 7, 2020, pp. 135-149. doi: http://dx.doi.org/10.20431/2349-0381.0707016.

Copyright: (C) 2020 Authors. This is an open-access article distributed under the terms of the Creative Commons Attribution License, which permits unrestricted use, distribution, and reproduction in any medium, provided the original author and source are credited. 